\title{
Qualitative Research in Psychology
}

\author{
Fattah Hanurawan \\ Faculty of Pscyhology, Malang State University \\ fhanurawan@yahoo.com
}

\begin{abstract}
Qualitative research is a research method studying subjective meaning of participant's world about an object researched. Steps of qualitative research in psychology are: researchers select research topic, researchers formulate research questions, researchers design the study, researchers collect data, researchersanalyses data, researchers generate findings, researchers validate findings, and researchers write research report. Some of the qualitative research designs are grounded research, phenomenology research, case study research, and ethnography research. In some situations, researchers often meet questions that reach beyond the prescription of the APA ethical guidelines concerning human participants. Researchers of qualitative research in psychology can generalize their research findings to other people, times, or treatments to the degree to which they are similar to other people, times, or treatments in the original research (naturalistic generalization). There are some strategies for expanding qualitative research as a research approach so the methodology can be accepted as one significant method in understanding psychological phenomena.
\end{abstract}

Keywords: qualitative research, psychology.

\section{Introduction}

Although in the American psychology, qualitative research methodology is still in the marginal position, this qualitative research approach is now well established in the United Kingdom. This approach has moved from the margins to mainstream in psychology in the United Kingdom (Frost, 2011) and also in the others European countries. Based on this reality, Indonesia psychology should also develop the qualitative research approach so the approach can be moved to the mainstream in psychology in Indonesia. In fact, there are growingso many psychological research in Indonesia used qualitative research methodology. Even, this qualitative research methodology has been taught in undergraduate level since 2000 in the faculty of psychology in many universities in Indonesia (Hanurawan, 2012).

In this article I would like to describe qualitative research in psychology. Main structure of this article can be listed as follows: qualitative research, qualitative research in psychology, steps of qualitative research in psychology, designs of qualitative research in psychology, designs of qualitative research in psychology, ethics in qualitative research in psychology, problem of generalizability of qualitative research in psychology, expansion strategies of qualitative research in psychology in Indonesia. 


\section{Qualitative Research}

There are so many definitions of qualitative research. Some of the definitions can be described as follows:

Connole, Smith, \& Wiseman (1993) describe the interpretive or qualitative research approach places priority on searching for and interpreting what is happening and being done according to the interpretation of the subjects or participants in the social activities being studied.

Denzin \& Lincoln (2000) statequalitative research is a situated activitythat locates researcher in the subjective world of participant or subject about the relevant phenomena. Qualitative research method tends to use inductive form of the scientific method to develop theory about phenomena in the world. Pure qualitative research relies on collection of qualitative data. Furthermore, the two experts of qualitative research, Denzin \& Lincoln (2000) state researchers in qualitative research study phenomena in their natural settings, attempting to interterpret the phenomena in terms of the meanings people being to them. Qualitative research included the studied use and collection of diversity of empirical materials, such as personal experience, life story, case study, interview, artifacts, cultural texts, and observational, that describe meanings in individuals' live.

Johnson \& Christensen (2004) state the qualitative research method is research approach using qualitative data. The qualitative data is nonnumerical data, e.g. words, documents, photos, and pictures.The Qualitative research tends to rely on inductive mode of the scientific method. The major purpose of the qualitative research is exploration and discovery in natural settings. The product of qualitative research is usually a narrative report with rich and detailed description.

Berg (2001) states qualitative research method deliberately answers to the questions by examining various social settings and individuals who inhabit these settings. Qualitative research method refers to meanings, concepts, definitions, characteristics, metaphors, symbols, and descriptions of things. The qualitative research method allows researchers to share in the understanding and perceptions of other and to explore how people structure and give meaning to their daily lives.

In conclusion, based on the many definitions of qualitative research, I can define qualitative research as a research method studying subjective meaning of participants world about an object studied(Hanurawan, 2012).

Connole, Smith, \& Wiseman (1993) described qualitative research method has four characteristics. The four characteristics can be listed as follows:

The researcher works in a natural setting. Investigating in a natural setting is devoted to acquire some deep understanding of the social, cultural, and historical setting.

Research may be designed and redesigned.It means all of the methods of qualitative research are flexible. Researcher can formulate or reformulate their concepts, design or model, data 
collection methods, data analysis methods, and results validation methods.

The research is concerned with social processes and with meaning. It means qualitative research is conducted within a theoretical framework that focuses upon social processes and the meanings which participants attribute to social situations.

Data collection and data analysis occur simultaneously. Flexibility in qualitative research also occurs throughout the collection and analysis of data. It means in qualitative research, data collection and data analysis is not a linear process, but occurs alongside each other. Theory is not imposed upon the data but emerges from the data.

\section{Qualitative Research in Psychology}

From above qualitative research definition, we can apply the definition to psychology. It becomes, qualitative research method in psychology is a study of subjective meaning of participants world about an objectof psychological or behaviorphenomena.

The object of psychological or behavior phenomena can be listed as follows:

- Self-concept.

- Social perception.

- Self-esteem.

- Social attitude.

- Social loafing.

- Anxiety.

- Persuasion.
Actually, qualitative research method hasa long history in psychology. The clinical case history is a qualitative research method (Dalton, Elias, \& Wandersman, 2007). We can see also from long history, many research in humanistic psychology and some social psychological research,used qualitative research method approach.

Psychology is in the postmodern period now. The postmodernism period is a period that is influenced by a postmodern philosophy. The postmodernism philosophy is a philosophy emphasizing the relativity of all knowledge, including science and methodology, focuses on how the knowledge of a particular time and place is constructed, especially on how power relation affect the creation and spread of ideas and beliefs (People \& Bailey, 2006). The postmodernism philosophy reached psychology and other sciences in the 1980s following the publication of Lyotard's The Postmodernism Condition: A Report of Knowledge (Nolas, 2011a).

In our postmodern period, the use of qualitative research in psychology can be seen in so many fields. The fields are:

- Health psychology.

- Organizational and industrial psychology.

- Community psychology (Dalton, Elias, \& Wandersman, 2007).

- Consumer psychology.

- Educational psychology.

- Developmental psychology.

Connole, Smith,\& Wiseman (1993) describe the main objectives of thequalitative (interpretive) research methods. The objectives can be described as follows: 
- Identifying subjects or participants' subjective meanings about the phenomena researched. It can be: definitions, feelings, interpretations, judgments.

- Providing descriptions, analyses, and explanations of the subjects or participants' subjective meanings about the phenomena researched.

- Making sense these descriptions, analyses, and explanationsintelligible to people through the preparation of qualitative or interpretive accounts.

- Reflecting and actingon the results with subjects or participants in the social activities being researched.

\section{Steps of Qualitative Research in Psychology}

Johnson \& Christensen (2004) listed the eight common steps of a qualitative research study. In this common steps, the qualitative researchers do not always follow the eight steps in the linear or sequential fashion. It is because qualitative research is fluid type of research. The steps can be described as follows:

Step 1. Researchers select research topic.

The qualitative researcher selects a research topic. In psychology, it can be psychologicalconstructs such as attitude, self-concept, persuasion etc.

Step 2. Researchers formulate research questions. Researchers develop initial questions at the beginning of the research process. However, the initial questions can be modified or changed during data collection and data analysis.
Step 3. Researchers design the study.

Soon after formulating research questions, the qualitative researchers choose design or model of their research relevant to the questions. The designs can be case study, phenomenology, grounded research, or ethnography.

Step 4. Researchers collect data.

There are some data collection methods in qualitative research. The data collection methods are: qualitative questionnaire, participant observation, in-depth interview, and secondary data (personal documents orofficial documents).

Step 5. Researchers analyze data.

There are some data analysis methods in qualitative research. The data analysis methods are: phenomenology analysis, grounded research analysis, ethnography analysis, or thematic analysis. One procedure of data analysis is to categorize the material and code (label) the data thereby produced so what is considered significant meaning can be seen (Connole, Smith, \& Wiseman,1993). Notes: Data collection and data analysis in qualitative research are often done concurrently (Johnson \& Christensen, 2004).

Step 6.Researchers generate findings.

Product of data analysis and interpretation is research findings. These findings can be seen as initial findings. The initial findings should be confirmed through validation process.

Step 7. Researchers validate findings.

In the validation process, researchers attempt to validate the data collected and their interpretations. There are some methods of 
validity in qualitative research, e.g. descriptive validity, interpretative validity, and theoretical validity.

Step 8.Researchers research report.

At the end of research process, researchers finish the research report. It contains title, abstract or summary, introduction, theoretical review, method, results, discussion, conclusions and recommendations, and references (Hanurawan, 2012).

\section{Designs of Qualitative Research in Psychology}

There are many designs or models/ approaches in qualitative research in psychology. Some of the designs are grounded research, phenomenology research, case study research, and ethnography research.

\section{Grounded Research}

Grounded research is a general methodology for developing theory that is grounded in data systematically collected and analyzed. The end results of the grounded research are usually a grounded theory (Johnson \& Christensen, 2004). The grounded research design is an approach used to study action and interaction and their meaning (Nolas, 2011a). A quantitative research approach in psychology tends to make rigid boundaries between researchers' theory, methods, and data. These boundaries are more blurred in qualitative research. The grounded research is an iterative process of data collection, analysis, and further data collection.
Grounded research design was firstly developed by two sociologist working at University of California, San Francisco, United States of America, i.e. Barney G. Glaser and Anselm L. Strauss, in the 1960s. Since its early days, grounded research design has been developed by a number of Barney G. Glaser and Anselm L. Strauss' students and others qualitative researchers. The grounded research is frequently used in qualitative research in fields such as social work, nursing, and clinical psychology (Nolas, 2011a).

The ontological view of grounded research design can be traced in early sociological thought, philosophy of pragmatism, and symbolic interactionism, which draw on French and North American social science at the end of the 19th century and turn of the 20th century. The epistemological view of grounded research designcan be traced in either positivist or social constructionism. The epistemology of grounded research design is essentially one of resistance to pre-existing knowledge, and managing the tension between the empirical phenomena and abstract concepts. The tension between the empirical phenomena and abstract concepts (theory) is managed by iterative process of data collection and data analysis. Knowledge in grounded theory is arrived through this process (Nolas, 2011a).

The primary data collection methods in the grounded research are interviews with 20-30 people and observations. Method ofdata analysis in the grounded research is called the constant comparative method. It begins with open coding, 
and then axial coding, and end with selective coding (it focuses on theoretical saturation). Data analysis in grounded research starts at first contact with the phenomenon being researched and it continues throughout the development of theory. It means data collection and data analysis in grounded research are concurrent and continual activities.

Report focus in the grounded research is a description ofpoeple and topic under researched. This report of grounded research ends with a presentation of grounded theory. It may also contain a list of propositions about phenomenon described and explained.

An example of a grounded research title in psychology is: The Self-Concept of Transsexuals in Malang City: A Grounded Research.

\section{Phenomenology}

Phenomenology research is a research approach or model in qualitative research with description of one or more individuals' consciousness and experience of a phenomenon. Phenomenology research design focuses on the way individuals interact with world of phenomena. The phenomena can be empirical objects or events to which they give meanings. Phenomenology is then the study of meanings of theses phenomena to particular people (Connole, Smith, \& Wiseman, 1993).

Phenomenology research is an approach to qualitative research that explores in detail personal lived experience to describe how people are making sense of their personal and social world. This researchmodel or approach used asa distinctive research approach in psychology in the mid-1990s. The philosophy of phenomenology, sociology of symbolic interactionism, and hermeneutics can be seen as basic foundations of phenomenology research.

An examples of the phenomenology research is: The Experience Of The Death Of Loved One Or The Experience Of Being Prejudiced By Members Of Other Groups. The main objective of phenomenological research is to describe a view participants' life worlds and to understand deeply their personal meanings constructed from their "life experience" of a phenomenon (death of loved one or being prejudiced by members of other groups) (Johnson \& Christensen, 2004).

Steps of phenomenology research can be listed as follows:

\section{The research question formulation}

Phenomenology research starts with formulating appropriate research questions. The questions are open and exploratory, focused on exploring participants' view, understandings and sense making within particular context of their lives. The type of research question appropriate for phenomenology research is likely to involve experience of considerable significance (phenomenal) to the participant. The phenomenon under study often concerned with current, emotive, and dilemmatic issues or issues involving reflection across the life course (Shinebourne, 2011).An example of phenomenology research question: How do transsexual person experience their self-esteem? 


\section{Selection of participants}

Participants can be selected by approaching relevant groups, personal contacts, or by "snowballing". The selected participants should fulfill characteristics and experience suitable to the phenomenon under study.

\section{Data Collection methods}

In a phenomenological research, the researcher collects data from several individuals and depicts their experience of a phenomenon. The method or technique of data collection usually used in thephenomenological research study is in-depth interview. In-depth interview can be used to obtain in-depth information about a participant's thoughts, beliefs, knowledge, reasoning, motivations, and feeling about a topic (phenomenon).Through this type of interview, the researcher attempts to reduce the statements to the common core (essence) of the experience as described by the research participants (Johnson \& Christensen, 2004).

The other data collection methods in phenomenological research are: observation (with intuitive inference drawn by researcher from the apparent reactions of participants to some objects or events), diary / log of reflection, and other expressive productions intended to be relating lived experience of the phenomenon (Connole, Smith, \& Wiseman, 1993).

\section{Analysis}

The collected data in a phenomenological research are analyzed using phenomenological analysis technique. This analysis is iterative, complex and creative that requires the researcher's reflective engagement in a dialogue with a participant's narrative and meanings. There are four stages of phenomenological data analysis technique. The four stages can described below:

In the first stage, researcher reads the whole transcript in a number of times to become understanding the data. In this stage, researcher also makes a detailed textual analysis with writing notes,comments, and reflections on the transcripts.

In the second stage, researcher returns to the transcript to transform the initial notes into emerging themes. Researcher tries to formulate concise phrases represented the themes.

Third Stage, researcher examines the emerging themes and clustering them together on the basis of conceptual similarities. Eventually the clusters are given a descriptive label that reflects the conceptual nature of the themes in each cluster.

In fourth stage a table of themes is produced. The table shows the structure of the main themes and sub-themes (Shinebourne, 2011).

\section{Case study}

Case study research is form of qualitative research that is focused on providing detailed account of one or more cases. This type of research focuses on each case as a whole unit as it exists in its real life context. It means case study research is holistic (Johnson \& Christensen, 2004). The purpose of case study research is to obtain and 
portray a rich descriptive account of meaning and experiences of people in an identified social setting (Connole, Smith, \& Wiseman, 1993).

Examples of case study research are: Developing students' critical thinking through the discussion of controversial issues: Case studies from Indonesia and Australia by Hanurawan\& Waterworth (2011) or Teachers' attitudes about the role of multicultural studies in reducing student prejudice by Hanurawan (1996).

Case study research uses multiple data collection methods. The multiple data collection methods are focus groups, in-depth interviews, observations, personal reflection journals, and documents. Any of the data collection methods can be used in the case study research can be used when they help answer research questions. Data analysis approach in a case study research begins with holistic description and search for themes shedding light on the case. Focus of the report of case study research is a description of the context and operation of the case or cases. It also provides discussion of themes, issues and implications (Johnson \& Christensen, 2004).

\section{Ethnography}

Ethnography research design has an objective to describe the cultural characteristics of a group of people and to describe cultural scenes. Ethnography research design is approach to qualitative research that originated in the discipline of anthropology science around the turn of 21 st century (Johnson \& Christensen, 2004). Psychology researchers who use ethnography research design usually study the cultural characteristics of a small group of people or individuals and cultural scenes as they relate to psychological issues.

Ethnography research design focuses on the rules that people sharing a culture use in executing their social interactions. In a ethnography research design, a researcher studies how individuals define, categorize, and interpret the natural (cultural) world (Connole, Smith, \& Wiseman, 1993).

An example of ethnography research design in psychology: An Ethnographic Study of Rural Javanese Ethnic Peasant's Attitude towards Globalization.

Primary data collection methods in ethnography research design are participant observation or non-participant observation over an extended period of time and interview with informants. In this context of data collection process, researchers in ethnography research rely on extended fieldwork (Johnson \& Christensen, 2004).

Data analysis technique in ethnography research is ethnography analysis technique with holistic description and search for cultural themes in data. Data collection and data analysisin ethnography research can be a concurrent process. It means, in ethnography research, researcher collect some data and analyzes those data, then return to the field to collect some more data and then analyze those data, and so on. Focus of the research report of ethnography research is a rich description of context and cultural themes (Johnson \& Christensen, 2004). 


\section{Ethics in Qualitative Research in Psychology}

Researcher is responsible for ensuring the safety and well-being of their researchparticipants and must obey to all the relevant ethical guidelines when conducting research. In this context, psychological research using human participants is regulated by APA Ethical Guidelines Concerning Human Participants in Research. The APA Ethical Guidelines Concerning Human Participants can be summarized as follows:

1. No harm

2. Privacy and confidentiality.

3. Institutional approval.

4. Competencies.

5. Record keeping.

6. Informed consent to research.

7. Dispensing with informed consent.

8. Offering inducement of research participation.

9. Debriefing (Gravetter \& Forzano, 2006).

Some of the questions of ethics in qualitative approaches to research are the same as in quantitative approaches. However, because to the characteristic and nature of qualitative research, there are some differences. Some of the differences are due to the information collected about people in qualitative research being more complete, detailed, and personal than more outsider approach. It can therefore provide more potent implications if released to others (Connole, Smith, \& Wiseman, 1993).

In some situations, researchers often meet questions that reach beyond the prescription of the APA (American Psychological Association) ethical guidelines concerning human participants.
The APA ethical guidelines seem designed with quantitative or positivistic psychological research, e.g. laboratory experimental research. The APA ethical guidelines views individuals as atomistic humans, not as members of social groups. In contrast, qualitative researchers study individuals' human in the context of specific social groups, such as members of ethnic communities or members of specific schools (Marecek, 2003).Based on this reason it can be concluded that in the qualitative research there are some specific ethical guidelines considered.

There are some examples of specific ethical guidelines for qualitative research in psychology. They are:

- Data are collected anonymously. In observation participation data collection method, the identity of participants is concealed in the analysis and writing report of the research (Nolas, 2011b). In the sense of confidentiality, participants should be assured that personal identities will be removed or changes from the written data and presentation of analysis (Esin, 2011).

- In the informal interview, researchers should always identity themselves. They ask permission from those they talk to for using the information provided in their research (Nolas, 2011b).

- Researchers have responsibility in considering the effects of the research both on the participants, wider groups, or wider communities(Esin, 2011).

- Researchers consider their role in the study. In this kind of ethic, researchers engage with issues relating to the scientific quality 
and the independence of the research, both in relation to the research sponsor and the researchers maintaining a critical stance towards their topic and participants (Nolas, 2011b).

Problem of Generalizability of Qualitative Research in Psychology

The concept of external validity has traditionally been attached to quantitative or positivistic research tradition. Responses by qualitative or interpretive researchers tradition have been mixed regarding whether or not this concept should be applied to qualitative or interpretive research.

Concept of external validity is important when researchers needs to generalize research findings to other people, times, or treatments. Actually, generalizability of or external validity is not main purpose of qualitative research in psychology. It is because many qualitative researchers are more interested in documenting particularistic findings than universalistic findings. The purpose of qualitative research is to describe a certain group a certain group of people or a certain event in a specific context, rather than a generate findings that are broadly applicable (Johnson \& Christensen, 2004).

Therefore in the moderate argument, external validity can be applied in qualitative research in psychology using rough generalization. Researchers of qualitative research in psychology can generalize their research findings to other people, times, or treatments to the degree to which they are similar to other people, times, or treatments in the original research. This process of generalizingon the basis of similarity can be defined as naturalistic generalization (Johnson \& Christensen, 2004).

To help readers of a psychological qualitative research report understand when they can generalize research findings, qualitative researchers must provide some informations as follows:

- Numbers of participants.

- Kind of participants.

- Method of selection of participants.

- Contextual or setting informations.

- Relationship between researcher and of participants during data collection process.

- Design of the research.

- Methods of data collection.

- Method of data analysis.

Expansion Strategies of Qualitative Research in Psychology in Indonesia

Few psychology faculties, psychological research institutions, and psychological professions in Indonesia use qualitative research as research methods. There are some strategies for expanding qualitative research as research methods so the methodology can be accepted as one significant method in understanding psychological phenomena. The strategies can be described as follows:

- At the undergraduate and graduate levels in psychology faculties in Indonesia, more spaces should be made in the psychology curriculum to incorporate the study of qualitative or interpretive paradigm and 
research tradition. Results of this kind of curriculum expansion will be a richer and more substantially encompassing profession, better able to respond to the increasing complex questions of the 21th century(Camic, Rhodes, \& Yardley, 2003). Undergraduate and graduate syllabi might include some qualitative studies (Marecek, 2003).

- At the undergraduate level, an introductory research methods class could begin with an examination of the assumptions of positivist (quantitative), interpretive (qualitative), and criticalparadigms (Hanurawan, 2010).

- In graduate education, one master's level course could provide more in-depth information about several of the qualitative methods(designs, data collection methods, data analysis methods, and findings validating methods).

- In doctorate education level, students' should have an integrative perspective about research methods (positivist, interpretive, and critical) and leave their doctorate program with a wider range of intellectual tools (Camic, Rhodes, \& Yardley, 2003).

- Textbookin psychology might make reference to the qualitative studies, both historic and contemporary (Marecek, 2003).

- Psychology journal should give sufficient spaces of qualitative studies.

- Research training, both in scientific setting and applied setting, should include rigorous courses in qualitative methodology.

- Psychology researchers and professionals sought alliances and collaborations other behavioral sciences and behavioral professions (anthropology, sociology, organizational behavior, management, and education)in the context of qualitative research and practices (Marecek, 2003).

\section{Conclusion}

There are some conclusions can be drawn from this critical description of qualitative research in psychology. The conclusions can be described below:

Qualitative research is a research method studying subjective meaning of participants world about an object researched.

Steps of qualitative research in psychology are: researchers select research topic, researchers formulate research questions, researchers design the study, researchers collect data, researchers analyze data, researchers generate findings, researchers validate findings, and researchers write research report.

Some of the qualitative research designs are grounded research, phenomenology research, case study research, and ethnography research.

In some situations, researchers often meet questions that reach beyond the prescription of the APA ethical guidelines concerning human participants.

Researchers of qualitative research in psychology can generalize their research findings to other people, times, or treatments to the degree to 
which they are similar to other people, times, or treatments in the original research (naturalistic generalization).
There are some strategies for expanding qualitative research as research methods so the methodology can be accepted as one significant method in understanding psychological phenomena.

\section{References}

Berg, B.L. (2001). Qualitative research methods for the social sciences. Needham Heights, MA: Allyn \& Bacon, A Pearson Education Company.

Camic, P.M., Rhodes, J.E., \& Yardley, L. (2003). Naming the stars: integrating qualitative methods into psychological research.P.M Camic, J.E., Rhodes \& L.Yardley, (Eds.) Qualitative research in psychology. Expanding perspectives in methodology and design (pp. 3-16). Washington, DC: American Psychological Association.

Connole,H.C., Smith, B.\& Wiseman, R. (1993). Research methodology 1: Issues and methods in research. Geelong: Faculty of Education Deakin University.

Dalton, J.H. Elias, M.J., \& Wandersman, A. (2007). Community psychology: linking individuals and communities. Belmont CA: Thomson.

Denzin, N.K. \& Lincoln, Y.S. (2000). Introduction: the discipline and practices of qualitative research. N.K. Denzin \& Y.S. Lincoln (Eds.). Handbook of qualitative research (pp. 1-29). Thousand Oaks, C.A.: Sage Publications.

Esin, C,(2011). Narrative analysis approaches. N. Frost (Ed.) Qualitative research methods psychology. Combining core approaches (pp. 16-43). Maidenhead, Berkshire: Open University Press, McGraw-Hill education.

Frost, N. (2011). Qualitative research in psychology. N. Frost (Ed.) Qualitative research methods psychology. Combining core approaches (pp. 3-15). Maidenhead, Berkshire: Open University Press, McGraw-Hill education.

Gravetter, F.J. \&Forzano, L.B. (2006). Research methods for the behavioral sciences. Belmont, CA: Thomson Wadsworth.

Hanurawan, F. (1996). Teachers'attitudes about the role of multicultural studies in reducing student prejudice. Unpublished research paper. Melbourne: Deakin University.

Hanurawan, F. (2010). Psikologi social, suatu pengantar. Bandung: PT Remaja Rosdakarya \& Universitas Negeri Malang.

Hanurawan, F. \& Waterworth, P. (2011). Developing students' critical thinking through the discussion of controversial issues: Case studies from Indonesia and Australia. The Social Educator. Journal of the Social Educator's Association of Australia, 29 (2), 12-20. 
Hanurawan, F. (2012).Metode penelitian kualitatif dalam ilmu psikologi. Surabaya: Komisi Peningkatan Kinerja Masyarakat (KPKM) Universitas Airlangga.

Johnson, B. \& Christensen, L. (2004). Educational research. Quantitative, qualitative, and mixed approaches. Boston: Pearson.

Marecek, J. (2003). Dancing through minefields: towards a qualitative stances in psychology. P.M. Camic, J.E. Rhodes, \& Yardley, L. (Eds.) Expanding perspectives in methodology and design (pp. 49-70). Washington, DC: American Psychological Association.

Nolas, S. (2011a). Grounded theory approach.N. Frost (Ed.) Qualitative research methods psychology. Combining core approaches (pp. 16-43). Maidenhead, Berkshire: Open University Press, McGraw-Hill Education.

Nolas, S. (2011b). Pragmatics of pluralistic qualitative research.N. Frost (Ed.) Qualitative research methods psychology. Combining core approaches (pp. 121-144). Maidenhead, Berkshire: Open University Press, McGraw-Hill education.

People, J. \& Bailey, G. (2006). Humanity.An introduction to cultural anthropology. Belmont CA: Thomson Higher Education.

Shinebourne, P. (2011). Interpretive phenomenological analysis. N. Frost (Ed.) Qualitative research methods psychology. Combining core approaches (pp. 44-65). Maidenhead, Berkshire: Open University Press, McGraw-Hill Education. 